Utah State University

DigitalCommons@USU

\title{
Valuing Environmental Changes in the Presence of Risk: An Update and Discussion of Some Empirical Issues
}

W. Douglass Shaw

Utah State University

Mary Riddel

Paul M. Jakus

Utah State University

Follow this and additional works at: https://digitalcommons.usu.edu/eri

\section{Recommended Citation}

Shaw, W. Douglass; Riddel, Mary; and Jakus, Paul M., "Valuing Environmental Changes in the Presence of Risk: An Update and Discussion of Some Empirical Issues" (2005). Economic Research Institute Study

Papers. Paper 299.

https://digitalcommons.usu.edu/eri/299

This Article is brought to you for free and open access by the Economics and Finance at DigitalCommons@USU. It has been accepted for inclusion in Economic Research Institute Study Papers by an authorized administrator of DigitalCommons@USU. For more information, please contact digitalcommons@usu.edu.

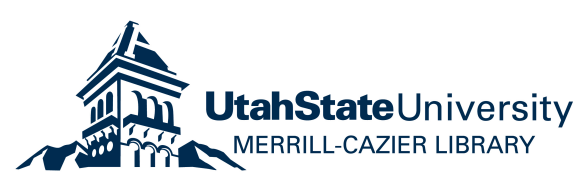


Economic Research Institute Study Paper

ERI \#2005-02

\title{
VALUING ENVIRONMENTAL CHANGES IN THE PRESENCE \\ OF RISK: AN UPDATE AND DISCUSSION OF SOME \\ EMPIRICAL ISSUES
}

\author{
by \\ W. DOUGLASS SHAW \\ Department of Agricultural Economics \\ Texas A\&M University \\ College Station, TX 77843-2124 \\ MARY RIDDEL \\ Department of Economics \\ University of Nevada \\ Las Vegas, NV 89154 \\ PAUL M. JAKUS \\ Department of Economics \\ Utah State University \\ 3530 Old Main Hill \\ Logan, UT 84322-3530
}

January 2005 


\title{
VALUING ENVIRONMENTAL CHANGES IN THE PRESENCE \\ OF RISK: AN UPDATE AND DISCUSSION OF SOME
}

EMPIRICAL ISSUES

\author{
W. Douglass Shaw, Associate Professor \\ Department of Agricultural Economics \\ Texas A\&M University \\ College Station, TX 77843-2124 \\ Mary Riddel, Assistant Professor \\ Department of Economics \\ University of Nevada \\ Las Vegas, NV 89154 \\ Paul M. Jakus, Professor \\ Department of Economics \\ Utah State University \\ 3530 Old Main Hill \\ Logan, UT 84322-3530
}

The analyses and views reported in this paper are those of the author(s). They are not necessarily endorsed by the Department of Economics or by Utah State University.

Utah State University is committed to the policy that all persons shall have equal access to its programs and employment without regard to race, color, creed, religion, national origin, sex, age, marital status, disability, public assistance status, veteran status, or sexual orientation.

Information on other titles in this series may be obtained from: Department of Economics, Utah State University, 3530 Old Main Hill, Logan, UT 84322-3530.

Copyright (c) 2005 by W. Douglass Shaw, Mary Riddel, and Paul M. Jakus. All rights reserved. Readers may make verbatim copies of this document for noncommercial purposes by any means, provided that this copyright notice appears on all such copies. 


\title{
VALUING ENVIRONMENTAL CHANGES IN THE PRESENCE \\ OF RISK: AN UPDATE AND DISCUSSION OF SOME \\ EMPIRICAL ISSUES \\ W. Douglass Shaw, Mary Riddel, and Paul M. Jakus
}

\begin{abstract}
The theory of ex-ante welfare measures is well establlished and has been addressed extensively in papers relating to the valuation of environmental resources when environmental variables have a random component. However, there have been many new developments in incorporating risks and uncertainty into economic models, and perhaps more importantly, there seems to be remaining confusion as to how to empirically implement such models. To date, a variety of estimation techniques have been utilized, with varying degrees of success in deriving an ex-ante welfare measure under risk. This manuscript assesses the state of the art by discussing the sources of risk, uncertainty, and error in utility models that incorporate risk. We are most interested in how to incorporate these ideas into empirical models and we examine how econometric estimation methods can best be used to obtain ex-ante welfare measures. We also present the current thinking on endogenous versus exogenous risks as well as subjective versus "expert” risk measures, and discuss some of the advantages and disadvantages likely to be encountered when using subjective-based risk estimates in empirical applications based on alternatives to the expected utility models.
\end{abstract}




\section{VALUING ENVIRONMENTAL CHANGES IN THE PRESENCE \\ OF RISK: AN UPDATE AND DISCUSSION OF SOME}

\section{EMPIRICAL ISSUES}

\section{Introduction}

In this manuscript we examine the current literature on valuing environmental changes that involve risk or uncertainty. We are most interested in how econometric estimation methods can be used in models to obtain ex-ante welfare measures under conditions of risk, but understanding the underlying microeconomic theory is naturally essential to pursue empirical modeling so that is also addressed. Examples below relate to changes in the environment that can affect human and ecological health and well-being.

Much of the risk-oriented economics literature is concerned with financial risk, where future income is uncertain and the focus is on trade offs between expected income and risk of investments. "Risk" typically measured by the variance of an asset portfolio (e.g. Hirschleifer; Pratt). While a great debt is owed to the authors of this literature, the work is perhaps only somewhat helpful in understanding how to model responses to environmental changes under risk. Another strand of economics literature focuses on human health and the risk of illness and death, but much of this literature is absent empirical values for risk changes and sometimes lacks a connection to the environment. It is nevertheless important, as it focuses on the theory relating to the value of a statistical life (VSL), and VSLs are regularly used in making environmental policy decisions (e.g. Berger et al.). Still another important strand of risk literature focuses on psychological models and risk perceptions (e.g. Slovic). Finally, there are several risk-oriented papers in the environmental

\footnotetext{
${ }^{1}$ This is naturally a highly selective review of the recent literature and we apologize to all those who have contributed important work in the area of modeling risk-taking behavior, especially as it relates to environmental changes. Our focus here is on papers that relate to empirical issues, but the reader interested in theory can see Schoemaker or Starmer's survey papers.
} 
economics and valuation literature, but is little connection between all of the above-mentioned areas of risk research. This manuscript is intended to help bridge that gap.

Many, if not all, current and serious environmental problems involve the risk of mortality, and to a lesser degree on morbidity. Problems also include the risk of impairment of ecological resources from exposure to contaminated air, water, food, or soils. Health and ecological effects from contaminants are rarely certain, though they were often treated that way in the environmental literature twenty years ago or more (e.g. Harrington and Portney's seminal work on air pollution and behavior). Even when health effects from exposure might be known, the exposure itself happens with some degree of risk. These risks can be quite small (Carson and Mitchell). Good examples of low probability exposure in the summer of 2002 was exposure to the West Nile virus in various places in the United States, and exposure to hoof and mouth disease in livestock in the United Kingdom in 1998. Arsenic in drinking water is another timely example of the connection between health risks and the environment in the United States. Siting or storage, and transportation of toxic and high-level radioactive nuclear waste is another good, current example (Kunreuther et al.).

Much has changed regarding how economists think about risks and uncertainty as compared to original thinking on the subject. Older analyses assume that risks faced by an individual were exogenous to them, and easily measurable by experts in assessing risks. Lately however, some believe that nearly all such risks can be controlled by an individual or household through selfprotection, making the risks endogenous (Agee and Crocker 1994; Shogren 1990). Shogren and Crocker (1999) use the example of species extinction risk, pointing out that habitat is often controlled by individual and group economic decisions; they put it simply: "Risk is endogenous." (p. 44). As another example, morbidity and mortality risks associated with drinking water laden 
with arsenic can be reduced through actions the household might take, including drinking bottled water, installing filters that are known to reduce arsenic concentrations to acceptable levels, or more drastically, even moving away from an area with high arsenic concentrations in the drinking water source.

Subjective assessments of risk by the public were clearly different than objective or expert assessments in the West Nile and hoof and mouth cases mentioned above. Many individuals exhibited concern about going outside and being bitten by mosquitoes in the United States, and walking trails in the hills in areas around the United Kingdom were closed in response to hoof and mouth, likely helping to drive a wedge between the public's assessment of risks and those made by the experts. This suggests the possibility that behavior should be empirically modeled in a different manner than when we assume that risks are exogenous to the individual, and we address this below.

The specific goals of the remainder of this paper are modest and fairly narrow in scope. We hope to describe current thinking on utility-theoretic models that incorporate risk, and describe appropriate welfare measures that might actually be estimated using data, all in the context of the environmental arena. First, we present some background on the conventional expected utility model and its application to environmental risk $^{2}$. Second, we discuss alternatives to the EU framework, looking at the differences in results when an individual's subjective assessment of risk is used rather than some exogenous determination of risk. Here we also consider the case of endogenous risk. Next, we consider stated and revealed preference approaches to actually empirically measuring values under risk, and finally, we offer the reader a list of the challenges ahead.

\footnotetext{
${ }^{2}$. The reader should note that imperfect information issues are sometimes thought to be synonymous with uncertainty, but in our view they are not, and this also is explained immediately below. Environmental concerns relate much more to uncertainty than poor or imperfect information in market or non-market settings.
} 


\section{Background and Literature}

We assume the reader is familiar with basics in risk and uncertainty, but at the outset, it is worth remembering that economists can deal best with well-defined risks, expressed as probabilities, rather than with total unknowns. Often individuals do not have perfect information and while "imperfect information" relates to uncertainty, and valuation issues are not equivalent, even though one can derive the value of information (Antonovitz and Roe). In the world of imperfect information we assume that agents make decisions on the basis of the information they have at the time the decision is made (e.g. Foster and Just). They may, or may not feel uncertain about something when their decision is made, and in fact may be clueless that the information they use to make their decision is incorrect. As Foster and Just (and more recently Leggett) show, one can model the agents' actual decisions using the information they actually have, and then construct a welfare measure using both the poor information and the "correct" information that influences their actual well-being. As an example, if a person believes their well water meets drinking water standards, they drink it, but suffer the health consequences that depend on the actual well water quality. Their true willingness to pay to reduce the risk of those health consequences incorporates both the incorrect information and the correct information. We believe this consideration of the role of information to be rather different than our focus here, for under uncertainty society may never have "perfectly correct" information that can be used to update welfare measures.

Though all uncertainty is complicated in economics, health risks influenced by environmental conditions are something economists can cope with. The 1980's produced several EPA-funded studies involving environmental risk that used some form of stated preferences to 
derive welfare measures. ${ }^{3}$ Physical scientists at EPA were, and still are, interested in risk because of the association between this and environmental problems in the health and ecological risk assessment arena. Valuation of impacts for cost-benefit analysis gave way to the literature on option values, and the option price. In the next section we review the microeconomic foundations for these welfare measures.

\subsection{The Expected Utility Model and Option Prices (OP)}

A large body of past literature explores issues connected to the option price (OP) and other ex-ante welfare measures, but the bulk of this literature addresses the microeconomic theory only and does not estimate or even offer a careful discussion of how to actually estimate ex-ante welfare measures using data; the discussion in these papers typically concludes well before one can glean the approach to estimating an equation that sheds light on a policy problem. ${ }^{5}$ Still, it is impossible to determine if an econometric model is consistent with the theory without carefully examining the theory first.

\subsubsection{The Expected Utility Model}

The derivation of the demand for goods and services in the presence of uncertainty owes virtually everything to the expected utility model (EUM) originally proposed by Bernoulli in 1738 and advanced by von Neumann and Morgenstern in 1947. As an example, suppose there is a relationship between health $(\mathrm{H})$ and environmental quality (q). Assume that the environmental quality level influences health in a continuous fashion so that $H=H(q)$ and $\partial H / \partial q>0$.

\footnotetext{
${ }^{3}$ A few examples are Fisher et al. and Smith and Desvouges (1987).

${ }^{4}$ Those unfamiliar with the environmental valuation literature should be warned that though related, option prices here are not the same as pricing stock options.
} 
Alternatively, if level $q^{0}$ is lower than level $q^{1}$, then in a discrete approach an individual who is healthy $(H)$ may turn to one deemed "sick" $(S)$. This is of course where many certainty studies began. Those interested in uncertainty have also used a household production function for health, with arguments such as the state of pretreatment health in it (e.g. see Besley, who assumes the state can be measured so that it is a bad rather than a good).

Let utility be a function of $H(q)$, the consumption of other goods and services (z), and on non-stochastic income $(Y)$. [We could let $\mathrm{U}$ depend on $\mathrm{q}$ and $\mathrm{H}$ separately, and also let $\mathrm{H}$ depend on q. ${ }^{6}$ ] Note that like most researchers we would probably make some simplifying assumption (e.g. separability) that allows us to ignore $\mathrm{z}$ so that data sets on consumption of every good do not have to be made available for empirical analysis. To develop a model with uncertainty, expected utility must depend on some probability distribution. Assume initially that environmental states, hence health risks, are exogenous: either estimable from some physical laws or at least supportable accurate data. The conventional EUM framework assumes both probabilities and outcomes, or the "prospects," are known and as the above notes, exogenous risks presume that the household cannot influence the level of risk they face. Utility when healthy is $U_{H}(Y, H(q))$, and when sick, $U_{S}(Y, H(q))$, and the probability of each discrete state is $\pi$, and $(1-\pi)$, respectively. Then expected utility is:

$$
E[U]=\pi U_{H}(Y, H(q))+(1-\pi) U_{S}(Y, H(q))
$$

\footnotetext{
${ }^{5}$ Innes and Cory provide a good example of a theoretical investigation, Larson and Flacco go further than this in suggesting general forms for expected demands, and Graham, in a lesser-known paper in 1983 also offers a few important suggestions for empirics.

${ }^{6}$ Adding a separate q term allows environmental quality to matter for reasons other than those that are health related.
} 
Assume that the expected utility function meets several conditions, including ordering, continuity, and independence. Continuity implies that any lottery can be represented by a certainty equivalent), and independence means that all outcomes are evaluated independently from other chances. One can maximize $\mathrm{E}[\mathrm{U}]$ subject to the usual budget $(\mathrm{Y})$ constraint, and derive optimality conditions. The resulting model of expected demands forms a basis for several theoretical welfare measures that have something to do with uncertainty. Of those, the most simple is perhaps the expected surplus, ES, which is the probability-weighted ex post consumers' surpluses.

From (1), if one knows that the consumer's surplus when healthy is $C S_{H}$, and when sick is $C S_{S}$, then

$$
E S=\pi C S_{H}+(1-\pi) C S_{S} .
$$

Graham (1983) shows that if one writes the von Neumann utility function for $\mathrm{i}=1$ to $\mathrm{n}$ states, as:

$$
E U(x, \pi, \beta, a, b) \equiv \sum_{i=1}^{n} \pi^{i}\left[a^{i} u\left(x^{i} ; \beta\right)+b^{i}\right]
$$

then in fact, when the consumer is allowed to make choices after the state is revealed, estimation only allows recovery of the $\beta$ parameter in (3). This revelation of an uncertainty-type of experiment is consistent with recovery of ES, but does not allow recovery of the parameters $a$ or $b$ (see Graham's 1983 paper for discussion).

The ES at first appears useful, but consider what ES represents when there is a program to improve drinking water quality. If an individual gets sick, which we assume happens with a probability equal to $(1-\pi)=0.25$, and we know that his surplus is $\$ 10$, then of course (1$\pi) C S_{S}=\$ 2.50$. If $C S_{H}$ is equal to $\$ 15$, then the ex post probability-weighted surplus is $\$ 13.75$. 
When there are more than two outcomes with associated probabilities, we would simply add these in the determination of ES over all outcomes. The ES is thus a useful measure when one can learn the ex post levels of surplus, but this implies that the dice, as it were, have been thrown, and everyone can see them. This is not too likely. Consider two timely examples: the nuclear waste storage dilemma and climate change. Both involve risks well into the future, and probably a lack of knowledge about specific probabilities. Such a world is hardly consistent with resolution to uncertainty, and this is especially true in the nuclear waste case (see Kunreuther et al., or more recently, Riddel, et al. or Riddel and Shaw 2003, 2004), where risks of accidents must be assessed over a 10,000 year period of waste storage. ${ }^{7}$ A truly ex-ante measure of the welfare benefit of a program to address one of these issues is more critical for policy makers than an ex post measure.

\subsubsection{The Option Price}

The OP is such an ex ante welfare measure and it can be theoretically generated in the context of a conventional EUM. To review the OP, consider a policy that would increase environmental quality from $q^{0}$ to $q^{1}$. The OP is:

(4) $\pi U_{H}\left(Y-O P, H\left(q^{1}\right)\right)+(1-\pi) U_{S}\left(Y-O P, H\left(q^{1}\right)\right)=\pi U_{H}\left(Y, H\left(q^{0}\right)\right)+(1-\pi) U_{S}\left(Y, H\left(q^{0}\right)\right)$

The OP is the payment made in advance of the resolution of uncertain conditions, such that the individual is indifferent between expected utility with better environmental quality less the payment, and expected utility with the original quality, without making the payment. The payment is equal in either state of health. As will be seen below, this definition is made very clear in Daniel Graham's (1981) framework, which assumes that contingent claims are made. There may exist a

\footnotetext{
${ }^{7}$ High-level radioactive wastes need 10,000 years to decay before mortality and morbidity risks from exposure fall to acceptable levels.
} 
whole locus of pairs of possible contingent payments, but in equation (4) we assume one contingent payment (equal to OP) in both states described there. More generally, one could assume that $\mathrm{H}$ or $q$ is a continuous random variable so that (4) requires integration over the continuous density function.

The key to welfare analysis in the EUM is in Graham's willingness to pay (WTP) locus of ordered pairs because it allows comparison of several concepts, including each conditional surplus measure, the sum of these after weighting by probabilities (the ES), the OP, the certainty point, and fair bet point (the one locus pair with the largest expected value). His graphical exposition (see our Figure 1) is very helpful, and the paper was the first clear presentation of the concepts, seminal in straightening out the issues. Key points about it follow.

First, Graham's WTP locus is by assumption nonlinear, reflecting the assumption of financial risk aversion for the individual. Financial risk aversion is met when the second derivative of the utility function with respect to the risky variable, holding other things constant, is negative. ${ }^{8}$ In Graham's original exposition, the contingent payments were related to a farmer's desire to fund construction of a dam given a Bernoulli weather distribution, so that the payments on the axes corresponded to a dry and wet state, but we draw our Figure 1 for sick (S) and healthy $(\mathrm{H})$ states. The 45-degree line shows all combinations of equal contingent payments, so the intersection of this line and the locus gives the OP.

Using the EU framework Graham (1981) defines option value (OV) as equal to OP less expected surplus (ES). ${ }^{9}$ On the graph in our Figure 1 as in Graham's (1981) figure, the OP happens

\footnotetext{
${ }^{8}$ As some still state that this means risk averse individuals decline all fair bets, it should be noted that Graham (1981) debunks this as a meaningful definition because even risk averse individuals would not necessarily decline purchase of fair insurance.

${ }^{9}$ Option value was a concept initiated by Weisbrod in 1964. All of these welfare measures are discussed briefly below, but more extensive discussion of the debate about the "sign and size" of option value (e.g. Cicchetti and Freeman; Graham 1981) can be found in Bishop or Smith (1992).
} 
to exceed the ES. The ES is found by drawing a line parallel to the odds ratio through the point $\mathrm{S}$ (the conventional surplus pair), and identifying the point at which this new line would cross the $45^{\circ}$ line. While in our case OV is positive, it needn't be. Though much time was spent on whether OV is positive or negative, Graham (1981) clearly shows that generally one cannot tell. He also shows that Cicchetti and Freeman's claim that OP generally exceeds ES is incorrect. In fact, if risk neutrality for Graham's weather gamble is assumed and there are no income effects, the Graham locus becomes linear, and ES and OP will be the same, unless some other way of relaxing these assumptions about risk references is introduced. We suspect that much of the focus in the 1980s on the OV was simply because many did not know how to ask the correct question to obtain an OP in a survey, or were not sure how to estimate an OP using the correctly obtained data.

Solving equation (4) for the OP yields an equation that is empirically tractable given standard, simple deterministic forms for utility functions often used in economics. With a convenient expression available, one can examine how the OP changes with changes in health risk or in environmental quality. For a change in the risk probability one obtains (see Smith, 1992):

$$
\text { (5) } \frac{d O P}{d \pi}=\frac{U_{H}\left(Y, H\left(q^{1}\right)\right)-U_{S}\left(Y, S\left(q^{o}\right)\right)}{\pi U_{H Y}+(1-\pi) U_{S Y}}
$$

where $U_{H Y}$ for example, is the partial derivative of the state-dependent-healthy utility function with respect to income, and similarly, $\mathrm{U}_{\mathrm{SY}}$ is this derivative when in the sick state. Economists naturally assume that $\mathrm{U}_{\mathrm{HY}}$ is positive. Of more interest is the sign and magnitude of $\mathrm{U}_{\mathrm{SY}}$, and at least allowing for the possibility that the marginal utility of a dollar is different than in the healthy state. At the extreme the two states are actually "alive" and "dead" and utility when dead is generally interpreted 
in health models as some sort of bequest-related utility (Querner; Jones-Lee). Intuition suggests that an individual's value of an additional dollar will be less when sick (or dead!) than when healthy, but the degree of difference is an empirical issue. Consider a very simple utility function, one where utility is linear in $\mathrm{Y}$, and $\mathrm{H}(\mathrm{q})$. Then equation (5) boils down to very simple differences in health produced via different levels of q, and respective constant marginal utility of income terms for each state. One could also examine $\mathrm{dOP} / \mathrm{dq}$, mapping through the health function as before, considering how changes in q change the health risks, and ultimately the OP. Intuition suggests that with higher health risks, an individual's ex ante payment for higher q will increase.

The relationships between various measures are so far clear. If the expected utility function is concave in $q$, Jensen's inequality can be applied and it implies that the OP will be greater than the expected surplus, ES. Generally, one can graph the locus of pairs of contingent payments, find the point on the locus where the pair are equal (where $\mathrm{P}_{\mathrm{S}}=\mathrm{P}_{\mathrm{H}}=\mathrm{OP}$ ), compare these to expected surplus if this is of interest, and analyze differences between the concepts as Graham does (again see figure 1). This may be relevant because there may be cases where Graham's framework suggests that alternatives to the OP are adequate, as in his special case when risks are individual ones. $^{10}$

\subsubsection{Risk Aversion in the EUM}

Up to this point we have treated the way that risk enters the utility function very simply, akin to financial risk models that simply let investment income be the only risk variable that drives the individual's behavior under uncertainty. The focus on financial risk may obscure the fact that what we are really interested in is the environmental risk, or typically, the mortality risk associated 
with an environmental problem. In fact there may be several potential sources of risk: either environmental quality, health status, or both, are random variables, and income could be also. With only one random variable, simple results are forthcoming in the EUM by examining the sign of the second derivative, as stated above.

There is obviously a connection between financial risk and environmental values, as we have indicated above: the shape of the WTP locus determines relationships between welfare measures for environmental changes under uncertainty, and that shape is determined by the implicit assumption of financial risk aversion (Pratt). It is tempting to assume, as many have, that if individuals are differing in their taste for financial risk, then more risk-averse individuals (averse in the sense of distaste for a mean-preserving spread of a lottery) will have a higher value for environmental protection, including the VSL. This may not be true.

When more than one risky good is considered, it is no longer possible to look at one partial second derivative and determine overall risk preference. Assumptions about different forms of risk preference, for example financial versus environmental risk, may in fact also result in the equivalence of several welfare measure concepts (Lange, 2001). ${ }^{11}$ In fact, Eeckhoudt and Hammitt show that conventional treatment of risk aversion is not enough to determine whether the value of preventing a bad risky outcome is higher for those who are risk averse than those who are not.

In their insightful theoretical paper, Eeckhoudt and Hammitt cite many studies before theirs, such as Fuchs and Zeckhauser, who state that "the more risk averse a person is with respect to

\footnotetext{
${ }^{10}$ In his 1981 paper, Graham uses the example of various individuals who have desires to visit an outdoor park, but one may not desire it in one state, while another does, in exactly the same state.
} 
wealth, the more he will pay to boost his probability of survival.” (Fuchs and Zeckhauser, p. 266). Eeckhoudt and Hammitt define $\mathrm{w}$ to be wealth, $\mathrm{u}_{\mathrm{a}}$ to be utililty when alive and $\mathrm{u}_{\mathrm{d}}$ to be utility when dead (usually bequest, or set to zero). Marginal utility of wealth in each state is denoted with $\mathrm{u}_{\mathrm{a}}{ }^{\prime}$ and $\mathrm{u}_{\mathrm{d}}$, respectively, and $\pi$ is mortality risk. With these definitions, in the conventional EUM, the VSL can be shown, using standard assumptions that survival is preferred to death and the individual is weakly risk averse to wealth to be:

$$
V S L=\frac{d w}{d \pi} \mid E U=0=\frac{u_{a}(w)-u_{d}(w)}{[1-\pi] u_{a}^{\prime}(w)+\pi u_{d}^{\prime}(w)}
$$

The VSL is therefore defined as the marginal rate of substitution between wealth and mortality risk, and equation (6) makes it clear that VSL is increasing in wealth, as long as the marginal utility of wealth when surviving is higher than when dead. Because so much environmental economics analysis in the 1980s and 1990s involved analysis of the VSL, we think that environmental economists came to believe that financial risk aversion was all that was important in analysis of impacts under uncertainty. Explicit in equation (6) is that $U=U(w, \pi)$. Mortality risk is obviously present as measured by $\pi$, but Eeckhoudt and Hammitt make assumptions about aversion to risk related to wealth that dictate curvature for the utility function. These assumptions about financial risk are not measured by $\pi$. Instead, they rely on the conventional Arrow-Pratt definition of risk, as indicated by the presence of a second derivative, with a negative sign.

However, using these same definitions, Eeckhoudt and Hammitt readily show that the effect of financial risk aversion on an individual's maximum willingness to pay (WTP) to

\footnotetext{
11 This seems to have been first noted by Pratt in 1964. Again note that when one omits any other source of randomness to characterize the risk other than income, then a linear in income utility function imposes risk
} 
partially reduce mortality risk is ambiguous. Clearly, there are actually two sources of risk to consider, not one: wealth and the risk related to mortality. Eeckhoudt and Hammitt's framework would perhaps be clearer if there was a discussion regarding the probability distribution defining mortality risk and the separate probability distribution defining financial risk. Otherwise, one might assume that the only risky aspect to wealth pertains to one's inability to earn income when dead, and here the mortality risk would generate the distribution on wealth in their two states. However, they follow a large literature and are not "wrong" in any sense: as statistics enters into any analysis involving risk, we simply think it more elegant to include a clear discussion of the sources for random variables.

When there is more than one source of risk the relationship between risk and WTP for reductions in risk depend on what other elements of the utility function are held constant while risk aversion in one dimension is increased. As a case in point, financial and environmental risks are not interchangeable: Eeckhoudt and Hammitt conclude that under many assumptions the relationship between financial risk aversion and the VSL that relates to mortality risk is ambiguous. Similarly, it is easy to imagine that an individual may have some tolerance for environmental risks whereas they are strongly financially risk averse. Thus, a well-specified utility function should likely incorporate both the financial and environmental risk preference.

In summary, most would agree that ex-ante welfare measures are the appropriate metric for analyzing costs or benefits when utility has a random component. The bulk of the literature does not offer a careful discussion of how to actually estimate ex-ante welfare measures. Deriving appropriate risk measures, and estimating the parameters of the expected utility model

neutrality. 
are empirical issues. The remainder of this paper focuses on issues related to estimating the parameters and values, such as the option price, of the expected utility model, and on what happens when risk assessments vary greatly across individuals ${ }^{12}$.

\section{Alternative Assumptions Regarding Uncertainty}

. The properties that EUM gambles are presumed to have are presented above and such a framework is restrictive. In particular, the independence axiom implies a set of linear, parallel and upward sloping indifference curves within the Machina-Marschak triangle. For those unfamiliar with this triangle, one may graph the preferences for gambles in probability space, analogous to graphing a set of indifference curves in two-dimensional quantity space. The resulting iso-utility curves are over the relative risks. The triangle is based on the assumption that there are three gambles. Naturally the probability of any third one, say prob $b_{2}$ is recovered from $1-$ prob $_{3}-$ prob $_{1}$. Conventionally, expected utility is of course linear in probabilities $\left[\partial E[u(X)] / \partial \pi_{i}=u\left(x_{i}\right)\right]$, which is a constant. The slope of the iso-utility curves is given by $\mathrm{d} p r o b_{3} / \mathrm{d} p r o b_{1}$, and so this is a positive constant as well.

The individual chooses the gambles taken by picking bundles under uncertainty. Independence requires that for all prospects, $\mathbf{s}, \mathbf{r}$, and $\mathbf{t}$ : if $\mathbf{s}$ is weakly preferred to $\mathbf{r}$ then $(\mathbf{s}, \mathbf{p} ; \mathbf{t}, 1-$ p) is weakly preferred to (r, p; t, 1-p) for all p. Querner puts this nicely: if one prize from a lottery is preferred to another prize, two lotteries only differing in these prizes should be ranked the same way as the prizes at hand. Complementary or substitution effects between different outcomes are ruled out. The usual predictions of the standard EUM (see Schoemaker) include that the:

1. estimated ex ante welfare (OP) should be sensitive to the magnitude of the risk change

\footnotetext{
${ }^{12}$ A reviewer notes that this might be a case for allowance of individual heterogeneity.
} 
2. OP should be roughly proportional to the change in risk

3. baseline level of risk should NOT influence OP in evaluating equal changes in risk (i.e. the ex ante willingness to pay to reduce risk by 1 percent when there are large risks should not be different than when there are small risks)

4. rate of substitution between risky choice A and another risky choice B remains constant throughout the range of risks that are faced.

These are strong predictions. Those who are critical of EUM claim that the independence axiom is unfounded, pointing to the sea of experimental and other evidence that contradicts the EUM's predictions. Some suggest that these violations of the independence axiom are particularly relevant to low probability events that would have devastating consequences if they happened. Mortality risks related to nuclear wastes, or earthquakes may fall into this category. Several authors continue to use the EUM coupled with exogenous probabilities (e.g. Cicchetti and Dubin), but as some authors have said, "the major lesson of recent research of individual behavior under risk is that it is not always consistent with the expected utility approach; in short, there is no generic model for evaluating behavior under risk" (Buschena and Zilberman).

By 1953, Allais had already demonstrated several contradictions flowing from the EUM's predictions for choices; others have recently categorized failures similar to the ones he outlines as common consequence or ratio effects (see Allias 1953, 1979; Starmer). Early simple experiments demonstrated that when choosing gambles, individuals often exhibited behavior inconsistent with an ability to rank gambles. Let an individual have to choose between a1 or a2, and between a 3 and a4, where $^{13}$ :

\footnotetext{
${ }^{13}$ We take this representation of Allais's paradox from Mason et al.'s paper.
} 
A1: $\$ 1$ million with probability $=1.0$

A2: $\$ 5$ million with prob. $=0.1, \$ 1$ million with prob. $=0.89, \$ 0$ with probability $=0.01$.

A3: $\$ 5$ million with prob. $=0.10, \$ 0$ with probability 0.90

A4: $\$ 1$ million with prob. $=0.11$, and $\$ 0$ with prob. $=0.89$

The lines connecting a1 to a2, and a3 to a4 are parallel, so if the individual's indifference curves are straight lines, as the EUM suggests, then he prefers a1 to a2 and a3 to a4, or a2 to a1 and a4 to a3. However, laboratory experiments shown subjects choose a1 and a3, and thus, the indifference curves cannot be straight lines. Observed choices led researchers to the conclusion that preferences were often reversed, that unequal gambles sometimes were treated as equal ones, or that individuals did not behave rationally.

Ex ante efficient choice may fail for a variety of reasons that are mostly in the realm of discrepancies between agent's assessments of the probabilities that describe the risks (Besley) and assessments by experts. The experimental economics literature, very much in vogue today (see Mason et al. for an example), has carefully examined issues of demand under uncertainty and the evidence generally supports the notion that people tend to overvalue reducing the probability of low risk events and undervalue risk reduction of high-risk events relative to the predictions of the EUM. Mason et al. find that indifference curves over lotteries are often concave rather than linear in probabilities. Despite evidence like this traditional EUM supporters are hesitant to support alternative theories that could potentially lead to non-unique choice sets. In response to these critics, many of the new theories of demand under uncertainty examine how nonlinear indifference curves over risky bundles or prospects might be incorporated while still ensuring unique demand relationships (Loomes and Sugden; Besley). 
In his survey article Starmer lumps many alternatives to the EUM together because they seek relaxation of this independence axiom. As an example, Machina (1982) introduced a generalized expected utility model (GEUM) to allow the expected utility indifference curves to fan out, recognizing that concavity of the probability derivatives are allowable even with non-expected utility preference functions. This generalized model relaxes the constant slope (i.e. the rate at which the prospects are traded for one another), as one moves from very low to very high risks, and this is fairly appealing. Machina's GEUM hypothesizes monotonicity (if one prospect first-order stochastically dominates another, the dominating prospect is preferred), and fanning-out, and some do not wish to see a requirement for fanning-out. Consider two pairs of prospects (R', S') and (R",S"). If preferences for the two pairs violate the EUM, than fanning-out implies that the violation is of the form such that the person is more risk-averse when evaluating the stochastically dominating prospects than when evaluating the dominated ones (Starmer and Sugden).

Yaari and several others have weighed in on the failures of the EUM (see Starmer), proposing variations on the standard EUM that may help in resolving paradoxes that arise in the EUM context. ${ }^{14}$ Eeckhoudt and Hammitt state that Yaari's dual non-expected utility theory is a special case of rank-dependent EU theory and cumulative prospect theory. In Yaari's model one simply uses linear utility functions in wealth $(\mathrm{w})$ and a probability weighting function $\mathrm{h}(\pi)$, so that $\mathrm{U}=[1-\mathrm{h}(\pi)] \mathrm{w}+\mathrm{h}(\pi) \beta \mathrm{w}$. Here the first term is the utility of wealth while alive and the second term the utility of wealth when dead. The weighting function has the properties that $h(0)=0, h(1)=1$, and $\mathrm{dh} / \mathrm{d} \pi>0$.

\footnotetext{
${ }^{14}$ Yaari's "dual theory" of choice under risk explains some of the Allais paradoxes.
} 
Several other alternatives (again see Starmer's excellent discussion) also relax the independence axiom, allowing the model to depend on the description of the probability distributions for the consequences. Perhaps the most well-known alternatives today are prospect theory (Kahneman and Tversky or Tversky and Kahneman 1981) and the prospective reference theory (PRT) of Viscusi $(1989,1990)$.

Kahneman and Tversky's prospect theory defines consequences as gains or losses relative to a reference point, which in their models relates to a level of wealth. In this sense a gamble can be treated quite differently if it involves a loss, or negative consequence, as opposed to a gain, or positive consequence. Strictly positive or negative consequences involve quite a different formulation of the utility maximization problem than conventional EUM: expected value is decomposed into a certain gain and a probabilistic one, or in the case of a negative consequence, a certain loss and a probabilistic one (see Starmer and Sugden).

Viscusi's PRT is similar to prospect theory. In it, Viscusi replaces $\pi$ in each of the above expressions with a function of $\pi$, say $\Pi($ Prob). Prospect theory (Kahneman and Tversky 1979) essentially would essentially do this also. For example, let the function be linear in the reference risk levels:

$$
\Pi(\operatorname{Pr} o b)=\frac{\left(\gamma \operatorname{Pr} o b+\alpha \quad P_{o}\right)}{(\gamma+\alpha)}
$$

Here the $P_{0}$ is the probability of the expert's assessment of the original outcome and Prob is the individual's prior assessment of risk. The $\gamma$ and $\alpha$ are the weights assigned to the informational content in each (the expert's and the person's own prior assessment of the risks.) If updating reduces the weight given to the prior, then the probability approximates the expert 
assessment. Starmer categorizes PRT as being a theory which helps explain "event splitting" effects. Here, a risky exposure might be described as producing several sub-risks, each with a smaller probability perhaps than one larger probability risk. When defined with the many subrisks, the consequence then gets more weight than otherwise.

Starmer deems some alternatives to the EUM as being unconventional in that they focus on how and why individuals make decisions; these include the view that the agent is boundedly rational. In one of the more interesting experiments we found, Starmer and Sugden (1989) tested various alternative theories, including the GEUM, Prospect Theory, and Quiggin's rank-dependent theory. The authors describe their own work as a pilot study, but they do not find any particular pattern in violations of the EUM, though most of their results indeed do suggest violations of the conventional theory. They were looking to see whether the statistics supported consistent fanningout of indifference curves over gambles, or consistent fanning-in, but they find support for either one being true in their data. Still, their pilot study may lend credence to incorporation of subjective risk assessments, discussed next.

\subsection{Subjective Risk Assessment and Perceptions}

Both prospect, and rank-dependent theory belong to the set of subjective expected utility theories (Starmer and Sugden). Economists may certainly argue about how to use subjective risk assessments, or what to do about these if they greatly differ from objective assessments, but perhaps irrefutable is that laypersons just do not always evaluate risks in the same way that experts do. Besley's example is the insurance agency's expert and the insured party. If people believe something different than what accumulated statistics or laws of science suggest about risk, then they will likely behave in ways based on their beliefs, not the statistics. Further, in some cases, they can 
make "bad" choices based on their beliefs. David Ropeik, director of risk communication at Harvard's Center for Risk Analysis cites the example of a mother of United Airlines attendant who drove on a trip rather than flew shortly after 9/11 and was killed in a car crash. He says she was "too afraid of low risk [flying] and ...her risk perception led her to a choice that was dangerous." (Dreifus). An individual's risk perceptions have been empirically shown in many cases to be quite distinct from other agent's technical assessment of risk (see Schoemaker for a summary).

Let the individual's risk perceptions be subjective probabilities, deemed prob. These might be used in lieu of, or at least to complement expertly assessed risks. ${ }^{15}$ It may be that the probability of an outcome (z) based on expert judgement $[\pi(\mathrm{z})]$ and the perceived probability of an outcome for the individual, $\operatorname{prob}(\mathrm{z})$, are roughly equal, and one might initially assume that the individual's assessment of risk can be treated as an exogenous and objectively determined variable. We could then simply modify the EUM by substituting these perceptions for actual risks into the usual equation for the EUM, as was suggested by several psychologists in the 1950's.

Very large divergences between expert and individual probabilities can be troubling. They may arise for several reasons. For example, Riddel et al. and Riddel and Shaw 2003 find consider the Department of Energy's (DOE) assessment of the risk of mortality from an accident during planned shipping of nuclear wastes, and assessments by Nevada residents who live near the proposed shipping routes and the final storage site of Yucca Mountain, Nevada. DOE's assessment of mortality risk from a transportation accident is about 2 in 10 million, about the same as dying

\footnotetext{
${ }^{15}$ The work of psychologists such as Paul Slovic (1987) suggests that in many instances "actual" risks are simply the assessment of risks according to another group of people, often deemed experts.
} 
from ingesting weed killer. ${ }^{16}$ On average, individuals in the estimating sample greatly over-estimate this tiny risk of DOE's: $\operatorname{prob}(\mathrm{z})$ is thousands of times higher than DOE's estimate. Respondents do this even when presented with an information brochure depicting a risk ladder with DOE's estimates, because of a lack of understanding of the problem, failure to comprehend these very small probabilities, a lack of knowledge, or information. If public policy requires action affecting individuals who will bear the risk, such as the nuclear waste transportation scenario, then a massive policy failure will occur unless the average household's perceptions are moved much closer to the agency assessment. As an aside, failures in the risk communication process (Smith and Desvousges; Riddel and Shaw 2003) leave a program in dire straights with respect to public support, as may be true for the DOE nuclear waste program in the future (Flynn and Slovic 1995).

Of course there may also be failures in the experts' original assessment, mitigating factors, strong preferences, and special characteristics of the risk-bearing households that complicate the risk communication process. Education or learning has the potential to move the individual's probabilities closer to $\pi(\mathrm{z})$, but this shift cannot be guaranteed. In fact, the experiments in risk communication in the 1980 s suggest that educating the public about risk is quite hard to do. A timely example is the recent example of the Center for Disease Control trying to educate the public regarding the real probability of dying from exposure to anthrax powder in an envelope. The CDC itself seemed unsure of the probability of morbidity or death with the type of anthrax being distributed in the mail.

\footnotetext{
${ }^{16}$ DOE obtained these estimates using statistics on accidents, and engineering tests, such as ramming aircraft engines into storage and shipping casks to see if they will break and leak
} 
So, if individual subjective probabilities remain important, a key issue concerns the manner in which these are introduced in any model. We consider three approaches here, using stated probabilities to replace the objective ones, using estimated probabilities, and using decision weights.

\subsection{Using Stated Probabilities in a Risk Model}

All of the above suggests that perhaps we should simply ask individuals to state what they think the probability of an outcome is. This approach was used by Crocker and Shogren (1991), and in a more advanced fashion, by Cameron (2003b). Here the modeler assumes that the stated probability is fixed, as a household's reported income is, and uses the variable accordingly. The attractiveness of this approach is that individuals can reveal heterogeneity in their expression of understanding and feeling about the mortality or morbidity risk related to an environmental change.

While appealing in its simplicity, this approach could pose problems. First, individuals may be poorly informed and change their beliefs substantially when new information is conveyed to them, strongly suggestive of treatment of the stated probability as a random variable, or the need for Bayesian updating. Second, one worries that if surveys are used to recover ex ante welfare measures, then each individual has a different understanding of the "good" being valued, because each assessment of risk accompanying the environmental change may vary. To offset some of the concerns, "alternative" theorists have proposed the use of decision weights.

Decision Weights

Decision weights are again consistent with subjective expected utility theory. Using them is a way to reconcile the difference between subjective and objective risk assessments, by introducing 
probability weighting functions: $V(s)=\sum f\left(w_{i}\right)\left(\operatorname{prob}_{i}\right)$, where again, s is a prospect, and here $f\left(w_{i}\right)$ is the weighting function. A weighting function can help explain observed behavior that contradicts what would be predicted under the EUM. The exact form that the weighting function takes is critical to our arguments below.

Quiggin (1991) summarizes the thinking on weighting functions. If the weighting function is linear and defined to map in the unit interval, he suggests that a correct weighting function simply forces the alternative model to become equivalent to the EUM. It is the nonlinear weighting functions that are more appealing on one hand, such as the s-shaped curves underlying much of the work to address discrepancies in losses and gains, but these nonlinear functions also create serious problems for the person who might be interested in welfare measures.

Fishburn noted that in many simple forms this type of weighting scheme leads to the expected utility function $\mathrm{V}(\mathrm{s})$ having the property of violating monotonicity of preferences. Such a violation would clearly spell trouble for welfare estimation, as the meaning of the welfare measure would be so different from any conventional notion. Subsequent schemes such as rankdependent expected utility theory (RDEU - Quiggin 1982) can ensure that V(s) is monotonic. Quiggin (1991) appears to view RDEU essentially as expected utility, but for a transformed probability distribution. The key difference between his notion of the RDEU and other weighting schemes is that the weights take into accord the entire probability distribution rather than only one individual probability $\left(\mathrm{p}_{\mathrm{i}}\right)$. Formally, the RDEU defines a weight as $\mathrm{h}_{\mathrm{i}}(\mathbf{P R O B})$, where PROB represents a vector of probabilities, while typical weighting schemes define a weight as $\mathrm{w}_{\mathrm{i}}\left(\mathrm{p}_{\mathrm{i}}\right)$. 
Finally, Quiggin and Chambers derive properties of generalized expected utility models concerning risk aversion. They demonstrate that while a preference function in the context of the EUM can display constant absolute risk aversion, or constant relative risk aversion (CARA or CRRA, respectively), it cannot display both, except in the trivial case of risk neutrality. Some of the generalized models however, can in fact display both properties. This is important in valuing environmental changes because individuals have choices to make regarding the functional form and the role that income, or another key variable plays in introducing various preferences for risk. We return to the empirical issues when using stated probabilities in Section 5, below.

\section{Empirical Approaches: Stated and Revealed Preference}

\subsection{Stated Preference Models}

Most studies that actually find empirical values for environmental changes under risk use at least some stated preference (SP) data: here we basically mean the modelers asked valuation questions directly, using some sort of survey format, and typically applied the well-known contingent valuation non-market valuation (CVM) approach. To get risk-related welfare measures the survey questionnaire has to describe uncertainty carefully, so that the respondent understands that environmental changes that occur with a meaningful probability, greater than or equal to zero and less than or equal to one. If the survey question is posed about the future, but with no degree of uncertainty introduced, then the resulting welfare measure may have a connection to the future, but might simply be an existence, bequest, or preservation value, none of which necessarily involve risk or uncertainty.

The manner in which the all-important probabilities are communicated to respondents in these surveys became a critical issue in the 1980's work (e.g., see Smith and Desvouges 1988), and 
some researchers are still quite pessimistic about the way individuals can incorporate probabilities into their understanding of risks, especially when valuation is the goal (see Hammit and Graham). However, many environmental economists have come to favor the risk ladder approach to communication (see Carson and Mitchell; Loomis and Duvair; Riddel, et al. for an application).

Good risk communication is important in any empirical SP model. Upon close inspection of many existing empirical SP studies it is difficult to know if the claims of estimating a particular ex ante welfare measure are valid: it is hard to tell whether what was estimated was really an OP (e.g. Brookshire, Eubanks, and Randall), or something else. This is partly because published papers do not often include the text of the survey questionnaire, but also because the source of the randomness and exactly how it is connected to risk or uncertainty, how it relates to underlying preferences, and the actual empirical model estimated, are not completely clear to the reader. ${ }^{17}$

\subsection{Revealed Preference}

Though stated preference models have been widely used to develop ex-ante welfare measures, we are aware of very few environmental economics studies that have used revealed preference (RP) data to obtain such measures for changes in non-market goods. ${ }^{18}$ Thinking about the issues involved in using RP data carefully, one can see why this is true: behaviors must have occurred that can shed light on risk-taking, and these behaviors and the associated risk levels (the probabilities) must somehow be uncovered for modeling purposes. To obtain RP data and derive

\footnotetext{
${ }^{17}$ Examples are Edwards (1988), Brookshire et al., and Loomis and DuVair. We note that Loomis and DuVair do not seem to let their empirical model depend on the probabilities relating to the risky outcomes, but they are careful to mention that their empirical model is ad hoc, and that their approach assumes everyone is risk neutral. Jakus, Riddel and Shaw discuss some of the difficulties in using RP data in a risk context.
} 
welfare measures, rather than ask directly for stated values that translate to an OP or some ex-ante welfare measure, one must obtain actual behavior with an implied ex ante payment in two or more uncertain states. The trick is in establishing clear, expressible utility differences so that an ex-ante welfare measure may be derived.

Åkerman et al. make what they claim is the very first attempt to use RP data to recover environmentally-related values under uncertainty, using mitigation costs to reduce the risk of getting cancer from radon exposure in one's home. Their experiment is ideal because they can observe behavior in response to risk. Unfortunately, they admit that their cost data are not quite up to standards, and a lack of detail in the published paper makes it hard to discern just how the risks were fully incorporated: it may just not be clearly explained, but the probabilities underlying getting cancer are absent in the econometric modeling described in their paper.

Some other environmentally-related studies examine the role of imperfect information do use RP data. In Agee and Crocker's study an observed behavior is whether the child was chelated to reduce the risks from exposure to lead. Dickie and Gerking examine behaviors in response to skin cancer risk. These observed behaviors play the same role as the observed keeping of potentially contaminated fish by anglers in Jakus and Shaw's study. Still, links between actual observed behaviors and perceived risks, as well as to objective risk measures are difficult to uncover. Incorporating the relevant probabilities into a pure RP model will indeed continue to be a challenge, especially if one wishes to incorporate ambiguity effects. In other arenas, economists have used

\footnotetext{
18 A kerman et al. use data on remedies to household radon problems and this may be the first RP-risk study, Agee and Crocker (1994) use RP data to explore the effect of information on perceived risk, and Jakus and Shaw (2003) is another recent exception. In their theoretical paper Larson and Flacco suggested that revealed preference (RP) models can be used to estimate ex-ante welfare measures under risk, but their discussion does not focus on issues in
} 
market data to examine ambiguity effects (e.g. Ho et al.), but this has not been done to our knowledge in environmental analysis.

Jakus and Shaw's (2003) recent work scratches the surface in that fishing behavior and estimated probabilities based on observed behavior are used to recover a risk-related welfare measure, but their survey was not specifically designed to reveal an ex ante measure of welfare: the authors make no claim that they have estimated Graham's option price. Other RP modelers are a bit vague about what the welfare measure actually is (an OP, OV, or an ES), ${ }^{19}$ so there may be interesting work ahead on the nature of the welfare measure in these models.

\subsection{Empirical Models and Sources of Randomness}

Whether SP or RP, empirical models typically add an error $(\varepsilon)$ to deterministic terms make them random variables. This error is assumed associated with the investigator's failure to recognize all variables that may influence an individual's utility. It does not originate in the individual's uncertainty about some event. In contrast, much of the empirical literature that deals with the individual's uncertainty does not consider measurement error, or incorporating the usual investigator's errors. As a preview to below, we might need to carefully consider the derivation of the ex ante welfare measure when measurement error is also present; a rich model might allow two random variables to enter into the derivation, one to represent measurement error and the other to incorporate the uncertainty.

Estimation is typically accomplished by assuming a mean zero errors, and the independent variables in the model are assumed non-stochastic whereas the dependent variable is stochastic. More formally, the usual sources of error are (i) omitted variables, (ii) error in measuring the 
dependent variable, and (iii) measurement error in the independent variables. All but the last are consistent with the Gauss-Markov assumptions of classical modeling, assuming that the omitted variables or measurement error are not correlated with the independent variables. The last source of error violates the classical assumptions. Using simple linear and semi-log demand functions and assuming no uncertainty on the part of the individual, Bockstael and Strand (1987) nicely illustrate that assumptions (i) to (iii) will yield different computed welfare measures. They illustrate that the assumed source of randomness makes a difference when computing certain welfare measures. Their argument is basically as follows.

Suppose CS is generally denoted as $\mathrm{f}(\mathrm{x})$, and $\mathrm{E}[\mathrm{CS}]=\mathrm{E}[\mathrm{f}(\mathrm{x})]$ denotes the expected value of CS when there are random variables. The potential problem is seen by again applying Jensen's inequality, when $\mathrm{f}(\mathrm{x})$ is a convex function:

$$
f[E(x)] \leq E[f[x]]
$$

The inequality sign in (6) is reversed when $f(x)$ is a concave function. The above implies here that a more general expected consumer's surplus will be equal to, or greater than, the surplus generated from expected demands. Bockstael and Strand conclude that for any consumer's surplus function that is convex in $\mathrm{x}$ (the demands), there will be a difference in consumer's surplus depending on the implicit assumption about the source of error.

We extend this discussion to allow for risk and uncertainty. Intuitively, if Bockstael and Strand obtain the result in models with no uncertainty, we might well expect that different assumptions about random variables in models with uncertainty also lead to different welfare

\footnotetext{
${ }^{19}$ For example, Agee and Crocker simply deem their welfare measure a marginal willingness to pay.
} 
measures. Using some of Larson and Flacco's suggestions, Kling demonstrates this using some simulations and literature estimates of option value.

As a specific example of what might be involved let $\hat{q}$ be the arsenic level in water drunk at the tap, a function of a naturally generated concentration of arsenic found in bedrock or soils $\eta$, but randomly distributed because of weather and precipitation patterns that affect the flow in ground or surface water. It may also be a random variable because of random patterns of exposure from drinking from a particular source, but the basic idea is that $\hat{q}=\eta+v$. The suggestion here is that a systemic portion of $\hat{q}$ helps explain the variation in arsenic concentrations in drinking water across different geological regions, but so does a random component, $v$. In this case a simple conditional indirect utility function $\mathrm{V}(\mathrm{y}, \mathrm{p}, \mathrm{q})$ is (a choice implies a nonzero price, $\mathrm{p}$ so that this $\mathrm{p}$ is subtracted from income, y) rewritten:

$$
V=\alpha+\beta(y-p)+\gamma(\eta+v)+\varepsilon
$$

Given this formulation, we perhaps ought to consider potential correlation between the random variables, say between the two sources of randomness, $v$ and $\varepsilon$, when developing a model that incorporates risk and measurement error. In the arsenic example we give above, $v$ and $\varepsilon$ are somewhat likely to be correlated, depending on whether the variations in the weather lead to both shocks in the measured arsenic level, and also the demand for water at the tap. Perhaps extreme temperatures would affect both. Again, the assumption about the source of $\varepsilon$ will be important, as will as the nature of the randomness underlying $v$. We know of no others that have considered the possibility of this process underlying $\mathrm{q}$ or $\hat{q}$, so there is no discussion in the literature of potential non-zero covariance terms that might arise. 
Another approach one could take is to let estimates of health risks themselves be measured with error, and deem that error "uncertainty." ${ }^{20}$ Let health $(H)$ be a random variable, so that:

$$
H=H^{*}+\varsigma
$$

Where $H^{*}$ might in turn be a deterministic function, for example, $H^{*}=a+q+b D$, where $q$ is again environmental quality but here it is not playing the direct role of a random variable, and $D$ represents health-related expenditures. As in the first part of this paper, a standard assumption is that $\frac{\partial H}{\partial D}>0$, i.e. that this type of spending improves health, perhaps through preventative medicines and procedures.

To our knowledge no one has implemented the ideas above, but we suggest that they can be. Below we give some cases involving uncertainty and offer examples of how to implement some of the more novel ideas empirically, largely ignoring the case where probabilities are exogenous and simply determined.

\section{The Challenges Ahead: Considering Specific Cases}

Here we consider specific cases involving the data, situation, and modeling, and lay out the challenges that lay ahead for empirical modelers.

[Case A] Suppose that $\mathrm{q}$ is random and discretely distributed. Further, suppose that $\mathrm{q}$ is measured with an indicator variable, with $\mathrm{q}=1 \mathrm{a}$ "poor quality" situation, and $\mathrm{q}=0$ the status quo, with good quality. Examples are when a leak from a gasoline or oil storage tank occurs or does not,

\footnotetext{
${ }^{20}$ Lichtenberg et al. say that a health risk means the probability that an individual selected randomly from the population contracts an adverse health effect. Health risk estimates are subject to error because the relationship between that risk and the variables that generate it cannot not be known with certainty. The term "uncertainty" is used as the measure of the magnitude of that error.
} 
or when nuclear waste is transported or not, meaning that accidents in transportation happen, or do not. Both events involve probabilities, and the next step is to determine what these are.

In a very simple model, we might assume that q follows a Bernoulli process. For example, when $\mathrm{q}$ is a nuclear waste accident, if it is not transported, then the probability of $\mathrm{q}=0$ is zero. However, with transport, a nonzero $\pi$ must be determined. In the expectation over $\mathrm{q}$ for a simple indirect utility function we have a simple model where $\mathrm{E}_{\mathrm{q}}\left[\mathrm{q}_{1}-\mathrm{q}_{\mathrm{o}}\right]=\mathrm{E}\left[\mathrm{q}_{1}\right]=\pi$. If this probability is exogenously given it may be the same for all individuals. We expect that this risk level, if it had any significant effect at all, would negatively influence a decision involving these risks. To empirically implement this model, one likely needs a discrete choice behavioral model because q implies this. One could, for example, write the conditional indirect utility functions, take expectations over q, resulting in forms that can be estimated.

Modifying equation (7) after taking expectations, one hopes to see an indirect utility function of the form $\mathrm{V}(\mathrm{p}, \mathrm{Y}, \mathrm{q}, \pi)$ so that the change in utility with respect to the risk can be evaluated. If estimated using the logit or probit discrete choice models, then the estimation also involves the usual investigator errors. If we see a conventional logit or probit model with no risk measure in the utility function, we do not believe that the model can be correctly incorporating uncertainty. If expectations of utility with respect to the random variable are properly taken, the OP ex ante measure can be found by examination of the expected utility differences (see Cameron 2003a).

This modeling quickly becomes much more complicated if we assume that risk is endogenous, and we think that while challenging, this is more interesting. For example, strictly speaking we might say that in the long run the household can move further away from the 
hazardous waste, reducing the risks from exposure. Or, in the case of nuclear waste shipping, households might move a safe distance away from the proposed routes. In that case, risk is not a simple exogenously determined probability there are two options for estimation.

One "option" for dealing with risk endogeneity is to make a simplifying assumption, as suggested by Graham (1981) in his special case for individual-risk. There Graham (1981) suggests that we simply redefine the states so that they are similar for all individuals. An example would be so that "state 1" is exposure and "state 2" is no-exposure. We don't find this to be particularly appealing for empirical work, but postpone discussion of option two until Case $\mathrm{C}$ is considered below.

[Case B] Another possibility one might face is that the density function used to implement uncertainty is again known and exogenous, but more complex than the above simple Bernoulli example, perhaps requiring evaluation of an integral (e.g. in the absence of a closed form). An assumption maintained is that the random process relating to $\mathrm{E}_{\mathrm{q}}$ is independent of that process underlying the usual error term. In this case there is an additional level of complexity making the usual recovery of welfare terms more difficult. Simulation methods are required in this case to estimate the ex ante welfare measure (e.g. Cameron 2003a), but simulation methods appear to be quite popular at this point (e.g. they are used in the mixed, random parameters, or heterogeneous logit models), so this alone is not likely to thwart efforts to recover welfare measures under uncertainty. Perhaps more interesting to the theorist would be careful consideration of how complex density functions relate to the Graham framework, where the contingent payments are simple functions of the probabilities. This is a key area where more work needs to be done. 
[Case C: Individual-specific risks] Here we consider the case where the probability density function for $\mathrm{q}$ is clearly individual-specific (there is a subjective risk assessment), or perhaps endogenous to the individual. We believe that subjective risks and endogenous risks are slightly different, but these concepts relate to alternatives to the EUM. One could have a subjective assessment of risk that differs substantially from one made by an "expert," but not be able to control that risk level. Alternatively, through self-protection (mitigation) one might control exposure and hence, health risks, making them endogenous to the household.

Suppose each individual has a process of forming perceptions of risk, so that $\pi$ varies for each individual, and likely depends on a host of factors. One might simply use a persons' stated probability in their EUM. This simple approach assumes that the stated probability is not a random variable, explained by factors in the household. Alternatively, a stated perceived risk can be assumed to be a random variable, estimated as a function of some explanatory variables, and used later, in choice modeling or valuation (see Agee and Crocker). In some recent efforts the modelers literally estimate each individual's perceived risk. In turn, this estimate feeds back into a model that determines choice.

Viscusi and others have also gone further than simply using the stated probabilities in such a simple manner (Viscusi 1989, 1990). Prospect Theory research (Tversky and Kahneman, 1981) indicates that gains and losses are valued differently under uncertainty, even if the monetary equivalent is the same in each case. A Bayesian spirit is associated with the alternative approaches suggested by these authors because individuals are thought to process information, update their priors, and perhaps reveal subjective, but posterior probabilities associated with risk. 
It has been suggested that with enough information and updating, the posterior should come quite close to the true objective or expert risk assessment or probability. This is simple to see in Viscusi's (1989) prospective reference theory (PRT), described above, which generalizes some earlier proposals by psychologists Smith (1992) shows that the expression for the option price in the PRT context can be viewed as the weighted average of two expected utility functions. One substitutes the $\Pi($ Prob) expression into the basic EUM equation (1). Typically regrouping terms leads to formulas that allow key features to be examined. Lattimore et al. (1992) generate similar functions, leading to a risk transformation function. Viscusi, Magat and Huber demonstrate that much of the above can be accomplished by generating reduced form equations for the risk perceptions, and in fact, much of Viscusi's empirical work does just this (e.g. Evans and Viscusi). However, we find no exact description of the ex ante welfare measure is in those studies, and often none is even estimated.

[Case D Endogenous Risk] Consider endogenous risks. Suppose that the household can affect the level of risk they face through certain actions and that we can collect data on individual-specific probabilities, possibly through stated probabilities, or possibly through a function that determines a household's probability. At the least, it would certainly seem appropriate to test for endogeneity, as self-protection might involve fairly low levels of effort and cost. For example, households with children facing mortality risk from second-hand smoke might control that risk by having the parents smoke outdoors, or in a room away from the children, or by adopting ventilation systems that reduce the smoke. Any situation where the parents of the household can mitigate against health risks 
for themselves or their children might fall into this category. How they control the risk of course depends on the information they have regarding these risks (see Agee and Crocker, 1994).

Here again it would seem appropriate to estimate the risk function first, before using any probability level in an expected utility model. As in the subjective risk case, many factors might predict the risk level a household actually faces, and these factors can change, thereby changing the probability level itself. If there are no concerns about econometric efficiency, then the risk functions can be estimated in a first stage, then fed back into a decision model. In principle, we see no difference between handling endogenous risk and subjective risks as random variables. Agee and Crocker implement this approach using data on child lead exposure, viewing the risk function as a posterior estimate, calculated as a weighted average of the average exogenous risk, and the mean of the parents' prior beliefs. Their perceived risk is:

$$
R=R\left(A c, L ; \gamma, i^{\prime}\right)
$$

where Ac are child care activities, L is chelation therapy, and the next two variables are family characteristics, and exogenous information about risks of lead exposure given to the family. This is not at all unlike the PRT model of Viscusi's in theory, but Agee and Crocker do not actually estimate an equation such as (11) above. Rather, they simply estimate the demand for chelation therapy for the child, being only able to observe whether the child was chelated or not. They interpret their probit estimates as being the probability of obtaining chelation therapy, which they say indirectly reflects the parents assessment of the risks to their child.

[Case E: Ambiguity] The last case we consider is a subset of Case $\mathrm{C}$ and involves individuals who are uncertain about the uncertainty, or who are "ambiguous." An ambiguity effect, (Amb), can be interpreted as the variance on the amount that the person is uncertain about the probability itself. If 
the individual states the probability of this with some ambiguity (see Ellsberg 1961; Einhorn and Hogarth; Viscusi and Chesson), then the randomness owed to the ambiguity might indeed relate to the randomness underlying the behaviors. The more uncertain the respondent is about the risks of the accident, the less utility she receives, which is consistent with Ellsberg's ambiguity aversion. This additional influence of ambiguity is novel in empirical models. It can be introduced by decomposing the event risk variable into two distinct random variables, one pertaining to the event and another to the ambiguity (see Riddel and Shaw 2004). Cameron (2003b) also allows for something like ambiguity in a more simple manner, and allowing for this effect appears to be important, so much more work lies ahead.

\section{Conclusion}

Environmental economists would understand much less than they do now if Graham had not laid out the relationship between possible welfare measures under uncertainty. He set our profession straight on the possible relationships between the ES, OV, and OP, explaining why the OP would be preferred in most situations. It is a bit difficult, but quite possible today for applied economists to collect data and estimate actual option price measures of welfare: Cameron's and Riddel and her coauthors' recent papers are good examples. Studies that incorporate uncertainty or risk and obtain values for environmental changes do so primarily using SP data. We are not disparaging of stated preference models, but many other economists are, so development of RP-data models likely needs more attention. Environmental economists need to catch up with economists who use RP data to value health risks related to automobile safety, risks to residents in houses in certain locations, etc. These studies incorporate behaviors that are costly to the individual, easily observed, and which 
provide a clue to preferences for risk by observing the trade off between money and risk reductions.

On the theoretical side, Smith (1992) hints we cannot view ex ante welfare measures from alternative models to the EUM in exactly the same manner as we would Graham's OP, but this issue has not yet been fully examined. Clearly, if one keeps the locus of payments for uncertain outcomes in mind, as in Figure 1, then introducing utility functions that themselves depend on nonlinear functions of the probabilities, or that in some way make the sign of the second derivative of the WTP locus ambiguous, may create a different ex ante welfare concept than what Graham depicts using the WTP locus. We do not believe that this means that alternative models lack usefulness in terms of welfare measurement, but it may be the case, in some situations, that resulting welfare measures will require careful scrutiny. 


\section{References}

Agee, M.D. and T.D. Crocker. 1994. "Parental and Social Valuations of Child Health Information.” Journal of Public Economics, Vol. 55, No. 1: 89-105.

Allias, M. 1953. Le Comportement de l'homme Rationnel Devant le Risque: Critique des Postulats Et Axiomes de 'ecole Americaine. Econometrica 21: 503-46.

Allias, M. 1979. The Foundations of a Positive Theory of Choice Involving Risk and a Criticism of the Postulates and Axioms of the American School. In Expected Utility Hypotheses and the Allais Paradox, M. Allais and O. Hagen, eds. Dordrecht: Reidel.

Åkerman, J.; F.R. Johnson; L. Bergman. 1991. Paying for Safety: Voluntary Reduction of Residential Radon Risks. Land Economics, Vol. 67 No. 4 (November): 435-46.

Antonovitz and T. Roe. 1986. "A Theoretical and Empirical Approach to the Value of Information in Risky Markets." Review of Economics and Statistics Vol. 68, No. 1 (Feb):105-114.

Berger, M.C.; G.C. Blomquist; D. Kenkel; and G.S. Tolley. 1987. Valuing Changes in Health Risks: A Comparison of Alternative Measures. Southern Ec. Journal, Vol. 53, No. 4(April): 967-84.

Besley, T. 1989. "Ex Ante Evaluation of Health States and the Provision for Ill-Health." The Economic Journal, Vol. 99 (March): 132-46.

Bishop, R.C. 1982. “Option Value: An Exposition and Extension.” Land Economics, Vol. 58, No. 1 (Feb): 1-15.

Bockstael, N. and I. Strand. 1987. The Effect of Common Sources of Regression Error on Benefit Estimates. Land Economics, 63 (1-Feb): 11-20.

Brookshire, D.S.; L.S. Eubanks; A. Randall. 1983. Estimating Option Prices and Existence Values for Wildlife Resources. Land Economics, Vol. 59, No. 1:1-15.

Buschena, David E. and David Zilberman. 1994. What Do We Know About Decision making Under Risk and Where Do We Go from Here? J. of Agri. and Resource Econ., vol. 19 (2):425-45.

Cameron, Trudy Ann. 2003a. "Individual option prices for climate change mitigation," Forthcoming, Journal of Public Economics.

Cameron, Trudy Ann. 2003b. "Updated subjective risks in the presence of conflicting information: Application to climate change," Revised Working Paper, Dept. of Economics, University of Oregon. 
Carson, Richard T. and Robert Cameron Mitchell. 2003. "Public Preferences Toward Environmental Risks: The Case of Trihalomethanes," forthcoming in Handbook of Contingent Valuation, A. Alberini, D. Bjornstad and J. Kahn (eds.). Brookfield, Vermont: Edward Elgar Press.

Cicchetti, C.J. and J.A. Dubin. 1994. A Microeconometric Analysis of Risk Aversion and the Decision to Self-Insure. J. of Political Economy, Vol. 102, No. 1: 169-186.

Cicchetti, C.J. and A.M. Freeman. 1971. “Option Demand and Consumer's Surplus: Further Comment.” Quarterly Journal of Economics, Vol. 85 (August): 528-39.

Crocker, T.D. and J.F. Shogren. 1991. Ex Ante Valuation of Atmospheric Visibility. Applied Economics, Vol. 23: 143-51.

Dickie, M. and S. Gerking. 1997. Genetic Risk Factors and Offsetting Behavior: The Case of Skin Cancer. J. of Risk and Uncertainty, Vol. 15: 81-97.

Dreifus, Claudia. 2002. “The Fear Factor Meets Its Match: a Conservation with David Ropeik.” New York Times, p. D2 (Science Section/Tuesday, December 3rd).

Edwards, Steven F. 1988. Option Prices for Groundwater Protection. J. of Environ. Econ. and Manage., Vol. 15, No. 4 (December): 475-487.

Eekhoudt, L.R. and J.K. Hammitt. 2004. "Does Risk Aversion Increase Value of Mortality Risk?” Forthcoming, J. of Environ. Econ. and Manage. [Presented at the AERE Workshop on Assessing and Managing Environmental and Public Health Risks (June, Bar Harbor, Maine, 2001).]

Ellsberg, Daniel. 1961. "Risk, Ambiguity and the Savage Axioms." Quarterly J. of Economics, 75 (4): 643-69.

Einhorn, Hillel J. and Robin Hogarth. 1997. "Decision Making under Ambiguity." In The Economics of Uncertainty, John Hey (editor). Cheltenham: Elgar Press.

Evans, W.N. and W.K. Viscusi. 1991. Estimation of State-Dependent Utility Functions Using Survey Data. Rev. of Econ. and Stat., Feb.: 94-104.

Fishburn, P. 1978. "On Hand's New Theory of Cardinal Utility and the Maximization of Expected Return.” J. of Political Economy, 86: 321-24.

Fisher, Ann et al. 1986. "New Information on the Value of Reducing Risk." Unpublished paper, U.S. Environmental Protection Agency, Washington DC (April 15). 
Flynn, J. and P. Slovic. 1995. "Yucca Mountain: A Crisis for Policy: Prospects for America's High-Level Nuclear Waste Program," Annual Review of Energy and the Environment, vol. 20: 83-118.

Foster, W. and R.E. Just. 1989. Measuring Welfare Effects of Product Contamination with Consumer Uncertainty. J. of Environ. Econ. and Manage. 17: 266-83.

Fuchs, V.R. and R. Zeckhauser. 1987. "Valuing Health- a Priceless Commodity." American Econ. Review 77: 263-68.

Graham, Daniel A. 1981. Cost Benefit Analysis Under Uncertainty American Econ. Review 71 No. 4 (September): 715-25.

Graham, Daniel A. 1983. “Estimating the 'State Dependent' Utility Function.” Natural Resources Journal, Vol. 23, No. 3 (July): 649-56.

Hammit, J.K. and J.D. Graham. 1999. Willingness to Pay for Health Protection: Inadequate Sensitivity to Probability? Journal of Risk and Uncertainty 8:33-62.

Harrington, W. and P. Portney, Valuing the benefits of health and safety regulation, Journal of Urban Economics, 22, 101-112 (1987).

Hirschleifer, J. 1965. "Investment Decision Under Uncertainty: Choice-Theoretic Approaches," Quarterly Journal of Economics, Vol. 79 (Nov.): 509-36.

Ho, J.; L. Keller; P. Keltyka. 2002. "Effects of Outcome and Probabilistic Ambiguity on Managerial Choices.” Journal of Risk and Uncertainty, Vol. 24: 47-74.

Innes, R. and D. Cory. 2001. The Economics of Safe Drinking Water. Land Economics, vol. 77 (1): 94-117.

Jakus, P. and W.D. Shaw. 2003. Perceived Risk and Product Choice: an Application to Recreation Site Choice. J. of Risk and Uncertainty, Vol. 26, No. 1: 77-92.

Jakus, P.; M. Riddel; W.D. Shaw. 2003. “Are Climbers Fools? Modeling Risky Recreation.” A chapter in The New Economics of Outdoor Recreation, N. D. Hanley, W. D. Shaw and R. E. Wright (eds.) Cheltenham, UK: Edward Elgar Press.

Jones-Lee, M.W. 1974. "The Value of Changes in the Probability of Death or Injury." J. of Political Economy 92: 835-49.

Kahneman, D. and A. Tversky. 1979. Prospect Theory: An Analysis of Decisions Under Risk." Econometrica, 47 (1):263-91. 
Kling, C.L. 1993. "An Assessment of the Empirical Magnitude of Option Values for Environmental Goods." Environmental and Resource Econ. (October).

Kunreuther, Howard et al. 1990. "Public Attitudes Toward Siting a High-Level Nuclear Waste Repository in Nevada." Risk Analysis, Vol. 10, No. 4: 469-84.

Lange, A. 2001. "A Note on Decisions Under Uncertainty: The Impact of the Choice of the Welfare Measure." Theory and Decision 51: 51-71.

Larson, Douglas M. and Paul R. Flacco. 1992. Measuring Option Prices from Market Behavior. J. of Environ. Econ. and Manage., Vol. 22, No 2 (March): 178-198.

Lattimore, P.K.; J.R. Baker; A.D. Witte. 1992. The Influence of Probability on Risky Choice: a Parametric Examination. J. of Econ. Behavior and Organization, Vol. 17: $377-400$.

Leggett, C. 2002. "Environmental Valuation with Imperfect Information: the Case of the Random Utility Model." Environmental and Resource Economics, 23 (1) 343-55.

Lichtenberg, E.; D. Zilberman; K.T. Bogen. 1989. Regulating Environmental Health Risks under Uncertainty: Groundwater Contamination in California. J. of Environ. Econ. and Manage., 17, No. 1 (July): 22-34.

Loomes, G. and R. Sugden. 1987. Some Implications of a More General Form of Regret Theory. J. Econ. Theory, 41: (2): 270-87.

Loomis, J.B. and P.H. duVair. 1993. Evaluating the Effect of Alternative Risk Communication Devices on Willingness to Pay: Results from a Dichotomous Choice Contingent Valuation Experiment. Land Economics, 69 No. 3 (August): 287-98.

Machina, M.J. 1982. "Expected Utility Theory without the Independence Axiom." Econometrica, 50: 277-323.

Machina, M.J. 1987. Choice Under Uncertainty: Problems Solved and Unsolved. J. of Economic Perspectives, Vol. 1, No. 1: 121-54.

Mason, C.F.; J.A. List; C. Settle; J. Shogren. 2000. Environmental Catastrophes and NonExpected Utility Maximization: An Experimental Evaluation. Discussion paper, University of Wyoming, Laramie, WY.

Querner, Immo 1994. "The Need for Alternatives to the Expected Utility Approach in Environmental Risk Economics or 'Who is Afraid of Russian Roulette?"' Chapter 4 (pp. 81-119) in Valuing the Environment: Methodology and Measurement Issues, Rudiger Pethig (ed.). Dordrecht: Kluwer Academic Publishers. 
Quiggin, J. 1982. A Theory of Anticipated Utility. J. of Economic Behavior and Organization, Vol. 3 (4): 323-43.

Quiggin, J. 1991 “Comparitive Statics for Rank Dependent Expected Utility Theory.” $J$. of Risk and Uncertainty, 4:339-350.

Quiggin, J. and R.G. Chambers. 1998. Risk Premiums and Benefit Measures for Generalized-Expected Utility Theories. J. of Risk and Uncertainty, 17: 121-37.

Pratt, J.W. 1964. Risk Aversion in the Small and the Large. Econometrica 32: 122-36.

Riddel, M. and W.D. Shaw. 2003. "Option Wealth and Bequest Values: The Value of Protecting Future Generations from the Health Risks of Nuclear Waste Storage." Land Economics, Vol. 79, No. 4 (November): 537-48.

Riddel, M. and W.D. Shaw. 2004. "Episodic Emissions: The Case of Nuclear Waste Transport.” Dept. of Economics, University of Nevada, Las Vegas 89154 [Revised, November].

Riddel, M.; C. Dwyer; W.D. Shaw. 2003. "Environmental Risk and Uncertainty: Insights from Yucca Mountain." Journal of Regional Science Vol. 47 No. 3 (August issue): 43557.

Schoemaker, P. 1982. "The Expected Utility Model: Its Variants, Purposes, Evidence and Limitations." J. of Economic Literature, Vol. 20 (June): 529-63.

Shaw, W.D.; M. Riddel; P. Jakus. 2004. "Can Graham's Ex Ante Welfare Framework Accommodate Subjective and Endogenous Risks?" Unpublished discussion paper, Dept. of Agricultural Economics, Texas A\& M University.

Shogren, J.F. 1990. "The Impact of Self-Protection and Self-Insurance on Individual Response to Risk." Journal of Risk and Uncertainty, Vol. 3: 191-204.

Shogren, J.F. and T.D. Crocker. 1999. "Risk and its Consequences." J. of Environmental Econ. and Manage., Vol. 37: 44-51.

Slovic, P. 1987. “Perception of Risk.” Science, Vol. 236: 280-85.

Smith, V.K. 1992. "Environmental Risk Perception and Valuation: Conventional Versus Prospective Reference Theory." Chapter 2 in The Social Response to Environmental Risk: Policy Formulation in an Age of Uncertainty, D.W. Bromley and K. Segerson (eds.). Boston: Kluwer Academic Press. 217 p.

Smith, V.K. and W.H. Desvousges. 1987. "An Empirical Analysis of the Economic Value of Risk Changes.” Journal of Political Economy, Vol. 95 (Feb): 89-114. 
Smith, V.K. and W.H. Desvousges. 1988. Risk Perception, Learning and Individual Behavior. American J. of Agri. Econ. Proceedings, Vol. 70, No. 5 (December): 1113-17.

Starmer, C. 2000. Developments in Non-Expected Utility Theory: the Hunt for a Descriptive Theory of Choice Under Risk. J. of Economic Literature, Vol. XXXVIII (June): 332-82.

Starmer, C. and R. Sugden. 1989. "Violations of the Independence Axiom in Common Ratio Problems: an Experimental Test of Some Competing Hypotheses." Annals of Operations Research, Vol. 19: 79-102.

Tversky, A. and D. Kahneman. 1981. The Framing of Decisions and the Psychology of Choice. Science, 211: 453-58.

Viscusi, W.K. 1989. Prospective Reference Theory: Toward an Explanation of the Paradoxes." J. of Risk and Uncertainty, Vol. 2 (September): 253-64.

Viscusi, W.K. 1990. Sources of Inconsistency in Societal Responses to Health Risks." American Economic Review Papers and Proceedings, Vol. 80 (May): 257-61.

Viscusi, V.K. and H. Chesson. 1999. "Hopes and Fears: The Conflicting Effects of Risk Ambiguity." Theory and Decision, Vol. 47: 153-78.

Viscusi, W.K. and W.N. Evans. 1990. "Utility Functions That Depend on Health Status: Estimates and Economic Implications." American Econ. Review, Vol. 79 (June): $353-74$.

Viscusi, V.K.; W.A. Magat; and J. Huber. 1999. Smoking Status and Public Responses to Ambiguous Scientific Risk Evidence. Southern Econ. Journal, Vol. 66 (2):25070.

Weisbrod, B.A. 1964. "Collective Consumption Services of Individual Consumption Goods.” Quarterly J. of Economics 78: 471-77.

Yaari, M.E. 1987. The Dual Theory of Choice Under Risk. Econometrica, Vol. 55, No. 1: 95-115. 


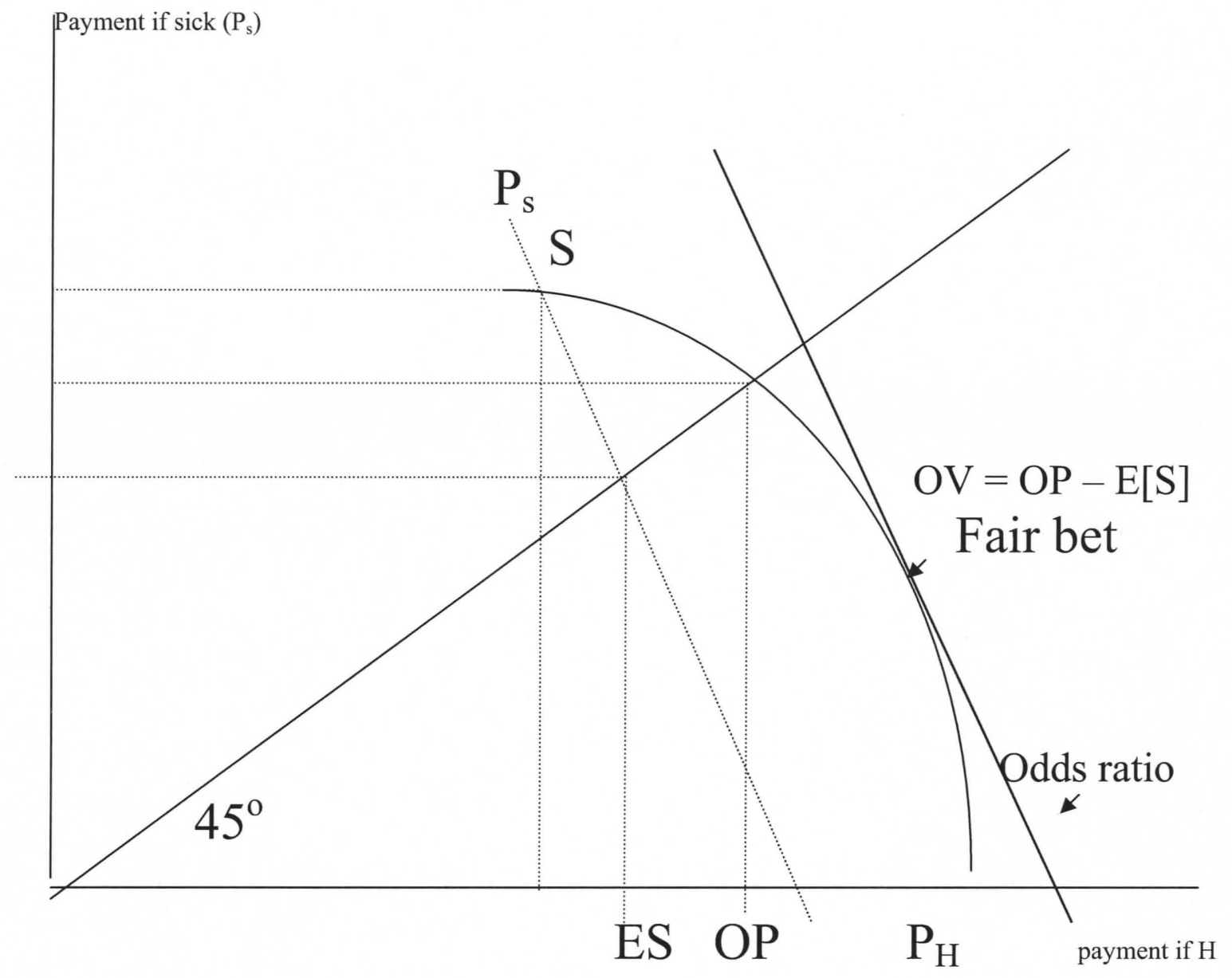

Figure 1. Graham's expected utility locus for any pair of payments, $\mathrm{P}_{2}$ and $\mathrm{P}_{1}$. Downward sloped straight line shows the odds ratio, or slope equal to - [Prob/1-prob]. Tangency with the WTP locus gives the "fairbet" point, and $\mathrm{S}$ is a pair of traditional surplus points. Parallel downward sloping line through $\mathrm{S}$ shows ES, at intersection with 45 degree line. The OP is where the payments are equal on the locus, at intersection point with 45 degree line. 


\title{
Valuing Environmental Changes in the Presence of Risk: An Update and Discussion of Some Empirical Issues
}

\author{
In press for: International Yearbook of Environmental and Resource Economics \\ A Survey of Current Issues 2005/2006 \\ Henk Folmer and Tom Tietenberg (editors) \\ Draft: October, 2004
}

by

\begin{abstract}
W. Douglass Shaw, Associate Professor
Department of Agricultural Economics

Texas A\&M University (TAMU 2124)

College Station, TX 77843-2124
\end{abstract}

(979) 845-6322

Mary Riddel, Assistant Professor

Department of Economics

University of Nevada

Las Vegas, NV 89154

(702) 895-3191

and

\author{
Paul M. Jakus, Professor \\ Department of Economics \\ Utah State University \\ 3530 Old Main Hill \\ Logan, UT 84322-3530
}

(435) 797-2309

E-mail addresses are wdshaw@ag.tamu.edu (contact author), mriddel@nevada.edu, and pjakus@econ.usu.edu. We thank Chris Starmer for encouragement of this work, Trudy Cameron for sharing her working papers on modeling responses to environmental changes under uncertainty, and Kerry Smith for his thoughtful comments on one of our related papers. Comments from seminar participants when related papers were given are acknowledged, including those at the Universities of Chicago, California State-Chico, Central Florida, Colorado, Denver, Wyoming, Colorado State University, and the U.S. Air Force Academy. We also thank the editors and an anonymous reviewer for comments that have improved this paper. This research was partially supported by the Texas and Utah Agricultural Experiment Stations, and for Riddel, from a UNLV faculty grant. 


\title{
Valuing Environmental Changes in the Presence of Risk: An Update and Discussion of Some Empirical Issues
}

\author{
Abstract \\ The theory of ex-ante welfare measures is well established and has been addressed extensively in \\ papers relating to the valuation of environmental resources when environmental variables have a \\ random component. However, there have been many new developments in incorporating risks and \\ uncertainty into economic models, and perhaps more importantly, there seems to be remaining \\ confusion as to how to empirically implement such models. To date, a variety of estimation \\ techniques have been utilized, with varying degrees of success in deriving an ex-ante welfare \\ measure under risk. This manuscript assesses the state of the art by discussing the sources of risk, \\ uncertainty, and error in utility models that incorporate risk. We are most interested in how to \\ incorporate these ideas into empirical models and we examine how econometric estimation methods \\ can best be used to obtain ex-ante welfare measures. We also present the current thinking on \\ endogenous versus exogenous risks as well as subjective versus "expert" risk measures, and discuss \\ some of the advantages and disadvantages likely to be encountered when using subjective-based \\ risk estimates in empirical applications based on alternatives to the expected utility models.
}




\section{Valuing Environmental Changes in the Presence of Risk: An Update and Discussion of Some Empirical Issues ${ }^{1}$}

\section{Introduction}

In this manuscript we examine the current literature on valuing environmental changes that involve risk or uncertainty. We are most interested in how econometric estimation methods can be used in models to obtain ex-ante welfare measures under conditions of risk, but understanding the underlying microeconomic theory is naturally essential to pursue empirical modeling so that is also addressed. Examples below relate to changes in the environment that can affect human and ecological health and well-being.

Much of the risk-oriented economics literature is concerned with financial risk, where future income is uncertain and the focus is on trade offs between expected income and risk of investments. "Risk" typically measured by the variance of an asset portfolio (e.g. Hirschleifer; Pratt). While a great debt is owed to the authors of this literature, the work is perhaps only somewhat helpful in understanding how to model responses to environmental changes under risk. Another strand of economics literature focuses on human health and the risk of illness and death, but much of this literature is absent empirical values for risk changes and sometimes lacks a connection to the environment. It is nevertheless important, as it focuses on the theory relating to the value of a statistical life (VSL), and VSLs are regularly used in making environmental policy decisions (e.g. Berger et al.). Still another important strand of risk literature focuses on psychological models and risk perceptions (e.g. Slovic). Finally, there are several risk-oriented papers in the environmental

\footnotetext{
${ }^{1}$ This is naturally a highly selective review of the recent literature and we apologize to all those who have contributed important work in the area of modeling risk-taking behavior, especially as it relates to environmental changes. Our focus here is on papers that relate to empirical issues, but the reader interested in theory can see Schoemaker or Starmer's survey papers.
} 


\section{References}

Agee, M.D. and T.D. Crocker. 1994. "Parental and Social Valuations of Child Health Information.” Journal of Public Economics, Vol. 55, No. 1: 89-105.

Allias, M. 1953. Le Comportement de l'homme Rationnel Devant le Risque: Critique des Postulats Et Axiomes de 'ecole Americaine. Econometrica 21: 503-46.

Allias, M. 1979. The Foundations of a Positive Theory of Choice Involving Risk and a Criticism of the Postulates and Axioms of the American School. In Expected Utility Hypotheses and the Allais Paradox, M. Allais and O. Hagen, eds. Dordrecht: Reidel.

Åkerman, J.; F.R. Johnson; L. Bergman. 1991. Paying for Safety: Voluntary Reduction of Residential Radon Risks. Land Economics, Vol. 67 No. 4 (November): 435-46.

Antonovitz and T. Roe. 1986. "A Theoretical and Empirical Approach to the Value of Information in Risky Markets.” Review of Economics and Statistics Vol. 68, No. 1 (Feb): 105-114.

Berger, M.C.; G.C. Blomquist; D. Kenkel; and G.S. Tolley. 1987. Valuing Changes in Health Risks: A Comparison of Alternative Measures. Southern Ec. Journal, Vol. 53, No. 4 (April): 967-84. 
Besley, T. 1989. "Ex Ante Evaluation of Health States and the Provision for Ill-Health." The Economic Journal, Vol. 99 (March): 132-46.

Bishop, R.C. 1982. “Option Value: An Exposition and Extension.” Land Economics, Vol. 58, No. 1 (Feb): 1-15.

Bockstael, N. and I. Strand. 1987. The Effect of Common Sources of Regression Error on Benefit Estimates. Land Economics, 63 (1-Feb): 11-20.

Brookshire, D.S.; L.S. Eubanks; A. Randall. 1983. Estimating Option Prices and Existence Values for Wildlife Resources. Land Economics, Vol. 59, No. 1:1-15.

Buschena, David E. and David Zilberman. 1994. What Do We Know About Decision making Under Risk and Where Do We Go from Here? J. of Agri. and Resource Econ., vol. 19 (2): 425-45.

Cameron, Trudy Ann. 2003a. "Individual option prices for climate change mitigation," Forthcoming, Journal of Public Economics.

Cameron, Trudy Ann. 2003b. "Updated subjective risks in the presence of conflicting information: Application to climate change," Revised Working Paper, Dept. of Economics, University of Oregon. 
Carson, Richard T. and Robert Cameron Mitchell. 2003. "Public Preferences Toward Environmental Risks: The Case of Trihalomethanes," forthcoming in Handbook of Contingent Valuation, A. Alberini, D. Bjornstad and J. Kahn (eds.). Brookfield, Vermont: Edward Elgar Press.

Cicchetti, C.J. and J.A. Dubin. 1994. A Microeconometric Analysis of Risk Aversion and the Decision to Self-Insure. J. of Political Economy, Vol. 102, No. 1: 169-186.

Cicchetti, C.J. and A.M. Freeman. 1971. "Option Demand and Consumer's Surplus: Further Comment." Quarterly Journal of Economics, Vol. 85 (August): 528-39.

Crocker, T.D. and J.F. Shogren. 1991. Ex Ante Valuation of Atmospheric Visibility. Applied Economics, Vol. 23: 143-51.

Dickie, M. and S. Gerking. 1997. Genetic Risk Factors and Offsetting Behavior: The Case of Skin Cancer. J. of Risk and Uncertainty, Vol. 15: 81-97.

Dreifus, Claudia. 2002. "The Fear Factor Meets Its Match: a Conservation with David Ropeik." New York Times, p. D2 (Science Section/Tuesday, December $3^{\text {rd }}$ ). 
Edwards, Steven F. 1988. Option Prices for Groundwater Protection. J. of Environ. Econ. and Manage., Vol. 15, No. 4 (December): 475-487.

Eekhoudt, L.R. and J.K. Hammitt. 2004. “Does Risk Aversion Increase Value of Mortality Risk?" Forthcoming, J. of Environ. Econ. and Manage. [Presented at the AERE Workshop on Assessing and Managing Environmental and Public Health Risks (June, Bar Harbor, Maine, 2001).]

Ellsberg, Daniel. 1961. "Risk, Ambiguity and the Savage Axioms." Quarterly J. of Economics, 75 (4): 643-69.

Einhorn, Hillel J. and Robin Hogarth. 1997. "Decision Making under Ambiguity." In The Economics of Uncertainty, John Hey (editor). Cheltenham: Elgar Press.

Evans, W.N. and W.K. Viscusi. 1991. Estimation of State-Dependent Utility Functions Using Survey Data. Rev. of Econ. and Stat., Feb.: 94-104.

Fishburn, P. 1978. “On Hand's New Theory of Cardinal Utility and the Maximization of Expected Return." J. of Political Economy, 86: 321-24.

Fisher, Ann et al. 1986. "New Information on the Value of Reducing Risk." Unpublished paper, U.S. Environmental Protection Agency, Washington DC (April 15). 
Flynn, J. and P. Slovic. 1995. "Yucca Mountain: A Crisis for Policy: Prospects for America’s High-Level Nuclear Waste Program," Annual Review of Energy and the Environment, vol. 20: 83-118.

Foster, W. and R.E. Just. 1989. Measuring Welfare Effects of Product Contamination with Consumer Uncertainty. J. of Environ. Econ. and Manage. 17: 266-83.

Fuchs, V.R. and R. Zeckhauser. 1987. "Valuing Health- a Priceless Commodity." American Econ. Review 77: 263-68.

Graham, Daniel A. 1981. Cost Benefit Analysis Under Uncertainty American Econ. Review 71 No. 4 (September): 715-25.

Graham, Daniel A. 1983. “Estimating the 'State Dependent' Utility Function.” Natural Resources Journal, Vol. 23, No. 3 (July): 649-56.

Hammit, J.K. and J.D. Graham. 1999. Willingness to Pay for Health Protection: Inadequate Sensitivity to Probability? Journal of Risk and Uncertainty 8:33-62.

Harrington, W. and P. Portney, Valuing the benefits of health and safety regulation, Journal of Urban Economics, 22, 101-112 (1987). 
Hirschleifer, J. 1965. "Investment Decision Under Uncertainty: Choice-Theoretic Approaches,” Quarterly Journal of Economics, Vol. 79 (Nov.): 509-36.

Ho, J.; L. Keller; P. Keltyka. 2002. "Effects of Outcome and Probabilistic Ambiguity on Managerial Choices." Journal of Risk and Uncertainty, Vol. 24: 47-74.

Innes, R. and D. Cory. 2001. The Economics of Safe Drinking Water. Land Economics, vol. 77 (1): 94-117.

Jakus, P. and W.D. Shaw. 2003. Perceived Risk and Product Choice: an Application to Recreation Site Choice. J. of Risk and Uncertainty, Vol. 26, No. 1: 77-92.

Jakus, P.; M. Riddel; W.D. Shaw. 2003. “Are Climbers Fools? Modeling Risky Recreation.” A chapter in The New Economics of Outdoor Recreation, N. D. Hanley, W. D. Shaw and R. E. Wright (eds.) Cheltenham, UK: Edward Elgar Press.

Jones-Lee, M.W. 1974. "The Value of Changes in the Probability of Death or Injury." J. of Political Economy 92: 835-49.

Kahneman, D. and A. Tversky. 1979. Prospect Theory: An Analysis of Decisions Under Risk.” Econometrica, 47 (1):263-91. 
Kling, C.L. 1993. "An Assessment of the Empirical Magnitude of Option Values for Environmental Goods.” Environmental and Resource Econ. (October).

Kunreuther, Howard et al. 1990. "Public Attitudes Toward Siting a High-Level Nuclear Waste Repository in Nevada." Risk Analysis, Vol. 10, No. 4: 469-84.

Lange, A. 2001. “A Note on Decisions Under Uncertainty: The Impact of the Choice of the Welfare Measure.” Theory and Decision 51: 51-71.

Larson, Douglas M. and Paul R. Flacco. 1992. Measuring Option Prices from Market Behavior. J. of Environ. Econ. and Manage., Vol. 22, No 2 (March): 178-198.

Lattimore, P.K.; J.R. Baker; A.D. Witte. 1992. The Influence of Probability on Risky Choice: a Parametric Examination. J. of Econ. Behavior and Organization, Vol. 17: 377-400.

Leggett, C. 2002. "Environmental Valuation with Imperfect Information: the Case of the Random Utility Model." Environmental and Resource Economics, 23 (1) 343-55.

Lichtenberg, E.; D. Zilberman; K.T. Bogen. 1989. Regulating Environmental Health Risks under Uncertainty: Groundwater Contamination in California. J. of Environ. Econ. and Manage., 17, No. 1 (July): 22-34. 
Loomes, G. and R. Sugden. 1987. Some Implications of a More General Form of Regret Theory. J. Econ. Theory, 41: (2): 270-87.

Loomis, J.B. and P.H. duVair. 1993. Evaluating the Effect of Alternative Risk Communication Devices on Willingness to Pay: Results from a Dichotomous Choice Contingent Valuation Experiment. Land Economics, 69 No. 3 (August): 287-98.

Machina, M.J. 1982. "Expected Utility Theory without the Independence Axiom.” Econometrica, 50: $277-323$.

Machina, M.J. 1987. Choice Under Uncertainty: Problems Solved and Unsolved. J. of Economic Perspectives, Vol. 1, No. 1: 121-54.

Mason, C.F.; J.A. List; C. Settle; J. Shogren. 2000. Environmental Catastrophes and NonExpected Utility Maximization: An Experimental Evaluation. Discussion paper, University of Wyoming, Laramie, WY.

Querner, Immo 1994. "The Need for Alternatives to the Expected Utility Approach in Environmental Risk Economics or "Who is Afraid of Russian Roulette?"' Chapter 4 (pp. 81-119) in Valuing the Environment: Methodology and Measurement Issues, Rudiger Pethig (ed.). Dordrecht: Kluwer Academic Publishers. 
Quiggin, J. 1982. A Theory of Anticipated Utility. J. of Economic Behavior and Organization, Vol. 3 (4): 323-43.

Quiggin, J. 1991 “Comparitive Statics for Rank Dependent Expected Utility Theory.” J. of Risk and Uncertainty, 4:339-350.

Quiggin, J. and R.G. Chambers. 1998. Risk Premiums and Benefit Measures for GeneralizedExpected Utility Theories. J. of Risk and Uncertainty, 17: 121-37.

Pratt, J.W. 1964. Risk Aversion in the Small and the Large. Econometrica 32: 122-36

Riddel, M. and W.D. Shaw. 2003. "Option Wealth and Bequest Values: The Value of Protecting Future Generations from the Health Risks of Nuclear Waste Storage." Land Economics, Vol. 79, No. 4 (November): 537-48.

Riddel, M. and W.D. Shaw. 2004. "Episodic Emissions: The Case of Nuclear Waste Transport." Dept. of Economics, University of Nevada, Las Vegas 89154 [Revised, November].

Riddel, M.; C. Dwyer; W.D. Shaw. 2003. "Environmental Risk and Uncertainty: Insights from Yucca Mountain." Journal of Regional Science Vol. 47 No. 3 (August issue): 435-57 
Schoemaker, P. 1982. "The Expected Utility Model: Its Variants, Purposes, Evidence and Limitations." J. of Economic Literature, Vol. 20 (June): 529-63.

Shaw, W.D.; M. Riddel; P. Jakus. 2004. "Can Graham's Ex Ante Welfare Framework Accommodate Subjective and Endogenous Risks?” Unpublished discussion paper, Dept. of Agricultural Economics, Texas A\& M University.

Shogren, J.F. 1990. "The Impact of Self-Protection and Self-Insurance on Individual Response to Risk." Journal of Risk and Uncertainty, Vol. 3: 191-204.

Shogren, J.F. and T.D. Crocker. 1999. "Risk and its Consequences." J. of Environmental Econ. and Manage., Vol. 37: 44-51.

Slovic, P. 1987. “Perception of Risk.” Science, Vol. 236: 280-85.

Smith, V.K. 1992. "Environmental Risk Perception and Valuation: Conventional Versus Prospective Reference Theory." Chapter 2 in The Social Response to Environmental Risk: Policy Formulation in an Age of Uncertainty, D.W. Bromley and K. Segerson (eds.). Boston: Kluwer Academic Press. 217 p.

Smith, V.K. and W.H. Desvousges. 1987. “An Empirical Analysis of the Economic Value of Risk Changes." Journal of Political Economy, Vol. 95 (Feb): 89-114. 
Smith, V.K. and W.H. Desvousges. 1988. Risk Perception, Learning and Individual Behavior. American J. of Agri. Econ. Proceedings, Vol. 70, No. 5 (December): 1113-17.

Starmer, C. 2000. Developments in Non-Expected Utility Theory: the Hunt for a Descriptive Theory of Choice Under Risk. J. of Economic Literature, Vol. XXXVIII (June): 332-82.

Starmer, C. and R. Sugden. 1989. "Violations of the Independence Axiom in Common Ratio Problems: an Experimental Test of Some Competing Hypotheses." Annals of Operations Research, Vol. 19: 79-102.

Tversky, A. and D. Kahneman. 1981. The Framing of Decisions and the Psychology of Choice. Science, 211: 453-58.

Viscusi, W.K. 1989. Prospective Reference Theory: Toward an Explanation of the Paradoxes." J. of Risk and Uncertainty, Vol. 2 (September): 253-64.

Viscusi, W.K. 1990. Sources of Inconsistency in Societal Responses to Health Risks. " American Economic Review Papers and Proceedings, Vol. 80 (May): 257-61.

Viscusi, V.K. and H. Chesson. 1999. "Hopes and Fears: The Conflicting Effects of Risk Ambiguity." Theory and Decision, Vol. 47: 153-78. 
Viscusi, W.K. and W.N. Evans. 1990. "Utility Functions That Depend on Health Status: Estimates and Economic Implications." American Econ. Review, Vol. 79 (June): 353-74.

Viscusi, V.K.; W.A. Magat; and J. Huber. 1999. Smoking Status and Public Responses to Ambiguous Scientific Risk Evidence. Southern Econ. Journal, Vol. 66 (2):250-70.

Weisbrod, B.A. 1964. "Collective Consumption Services of Individual Consumption Goods." Quarterly J. of Economics 78: 471-77.

Yaari, M.E. 1987. The Dual Theory of Choice Under Risk. Econometrica, Vol. 55, No. 1: 95-115 